\title{
Selective effects of vibration on monosynaptic and late EMG responses in human soleus muscle after stimulation of the posterior tibial nerve or a tendon
} tap

\author{
A. V A N B O X T E L \\ From the Department of Psychology, Physiological Psychology Section, Tilburg University, \\ Tilburg. the Netherlands
}

SUMM A RY In normal subjects it was possible to evoke tendon and Hoffman reflexes which were followed by late EMG responses with a latency of 150-250 ms after the reflex stimuli. Analysis of the covariations of reflexes and late responses revealed that muscle spindle sensitivity and strength of the preceding twitch are not essential factors in determining the occurrence of the late responses as opposed to excitability changes within the spinal cord. Inhibition of monosynaptic reflexes and facilitation of late EMG responses to vibration indicate a difference in central pathways. A polysynaptic pathway may be involved in the late responses.

In normal subjects, electrical stimulation of the posterior tibial nerve or a tap to the Achilles tendon is, under isometric conditions, in the relaxed soleus muscle usually only followed by a monosynaptic EMG response. During a weak isometric voluntary contraction of the calf muscles, the monosynaptic reflex may be followed by one or more late EMG responses at regular intervals of 150-250 ms (Agarwal and Gottlieb, 1972; Stein and Bawa, 1976; Hayes and Clarke, 1978). The late responses may be viewed as weakly damped oscillations in the monosynaptic stretch reflex arc. It has been found that primary muscle spindle endings discharge during the relaxation phase of an electrically induced twitch, both during a weak isometric contraction (Hagbarth and Vallbo, 1968) and in relaxed muscles (Wallin et al., 1973; Szumski et al., 1974). The response of the primary spindle endings may elicit a succeeding EMG discharge. In agreement with this view, the latency of the late response was found to be related to the duration of the preceding contraction and the results of linear systems analysis were consistent with the presumed role of primary endings (Stein and Bawa, 1976).

Address for reprint requests: A. van Boxtel, Tilburg University, Department of Psychology, Postbus 90153, 5000 LE Tilburg, the Netherlands.

Accepted 9 April 1979
The same mechanism is involved in ankle clonus in spastic patients. The muscle spindles are silent during the contraction phase and fire during the relaxation phase of the clonus twitches (Szumski et al., 1974; Hagbarth et al., 1975b). The clonic oscillations might be explained by an increased dynamic fusimotor tone which is postulated in spastic patients (Dietrichson, 1973; Szumski et al., 1974).

It has been argued that, in addition to twitchevoked input, long-loop responses to the original reflex stimuli may also contribute to the late response which follows a monosynaptic reflex (Tábořiková and Sax, 1969). Based on findings with the recovery of monosynaptic reflex amplitudes after subliminal conditioning stimuli in normal and spinal man, it may be concluded provisionally that long latency (150-250 ms) facilitatory effects may occur in normal subjects (Tábořiková and Sax, 1969; Gassel, 1970a; Delwaide, 1971; Robinson et al., 1979) and in patients with complete spinal transection (Masland, 1972), while type Ia nerve fibres are not involved in these effects (Katz et al., 1977). This supports Gassel's (1970b) hypothesis that long latency facilitatory influences are transmitted by cutaneous fibres at the spinal level. However, if the conditioning stimulus elicits a monosynaptic reflex, the stimulus-evoked input will be of less 
importance than the twitch-evoked input in evoking a late EMG response.

Although clonic afterdischarges may be easily conceived as monosynaptic responses to relaxation of twitches, vibration of the muscle gives paradoxical results. Monosynaptic reflexes are generally suppressed during vibration, largely because of presynaptic inhibition (Gillies et al., 1969; Delwaide, 1971; Dindar and Verrier, 1975) and, in the case of the tendon reflex, of a less effective response of the primary endings to the tendon tap during vibration (Burke et al., 1976). On the contrary, clonus-like oscillations may be initiated or exaggerated by vibration, both in spastic patients and normal subjects (Hagbarth and Eklund, 1966; Burke et al., 1972; Kanda et al., 1973). The discrepancy between the effect of vibration on monosynaptic reflexes and on clonic oscillations is not consistent with the assumption that both are transmitted by the same monosynaptic pathway.

In this study monosynaptic reflexes, followed by late EMG responses, were evoked in the soleus muscle of normal subjects. The relationship between Hoffmann (H) and Achilles tendon (T) reflexes on the one hand and the late response on the other was analysed to uncover common central and peripheral influences on both types of responses. We also tested whether they reacted in a similar way to vibration of the soleus muscle.

\section{Methods}

The experiments were carried out in a soundproof electrically shielded room. The subjects were comfortably seated in a specially designed armchair with hip and knee flexed at about $120^{\circ}$ and the ankle at about $100^{\circ}$. The feet were strapped rigidly to the foot pedal to obtain nearly isometric conditions. Tendon reflexes were evoked by a Brüel and Kjaer 4809 vibration exciter, which produced tendon taps of $8 \mathrm{~ms}$ duration. Hoffmann reflexes were evoked by stimulating the posterior tibial nerve percutaneously in the popliteal fossa with a $1 \mathrm{~ms}$ rectangular electric current wave. Surface recording electrodes were placed $40 \mathrm{~mm}$ apart on the distal part of the soleus muscle and on the belly of the anterior tibial muscle. The intensity of the reflex stimuli was adjusted to obtain submaximal reflex amplitudes: $H$ reflexes were not preceded by a direct motor response or only a small one.

Vibration was applied by strapping a Heiwa TVR HV-11D cylindrical vibrator to the belly of the triceps surae muscle. Initially vibration fre- quencies of 50 and $100 \mathrm{~Hz}$ were tested. Since no systematic differences in results were obtained, a frequency of $100 \mathrm{~Hz}$ was used in the further experiments.

The EMG potentials were amplified (response $3 \mathrm{~dB}$ down at 5.3 and $1000 \mathrm{~Hz}$ ) and recorded on magnetic tape. Signals which marked events like vibration and instructions to start and stop voluntary contractions were also recorded. The data were analysed by a PDP $11 / 10$ computer. The EMG potentials were sampled at a rate of $2048 \mathrm{~Hz}$ and could be shown on a visual display. By applying time windows the monosynaptic potential and the late EMG response could be distinguished from the rest of the sample record. Subtracting the lowest from the highest values within the time windows yielded the peak-to-peak amplitudes of reflexes and late responses. The results were recorded on an $\mathrm{X}-\mathrm{Y}$ reccrder.

The subjects were instructed to keep the legs as relaxed as possible throughout the experiment unless they were asked to make isometric contractions. Several types of experiments were done. (1) $\mathrm{T}$ and $\mathrm{H}$ reflexes were evoked at rates varyingo between $1 / \mathrm{s}$ and $5 / \mathrm{s}$ in eight and seven subjects o respectively. The influence of the stimulus fre⿻ి quency on the occurrence of late EMG response was studied. (2) $\mathrm{T}$ and $\mathrm{H}$ reflexes were evoked ato a rate of $3 / \mathrm{s}$ in 10 and eight subjects respectively At least 1000 reflexes were recorded to study the relation between the spontaneous variations in reflex and late response amplitudes. The same was? done in five subjects but now $\mathrm{T}$ and $\mathrm{H}$ reflexes were evoked alternately in the same leg. In this case at least 2000 reflexes $(1000 \mathrm{~T}$ and $1000 \mathrm{H}$ reflexes) were recorded. The latter type of experiment was repeated in four subjects while relaxation was alternated with weak isometric contraction of the calf muscles on a signal given by the experimenter. (3) $\mathrm{T}$ and $\mathrm{H}$ reflexes were evoked at a rate of $3 / \mathrm{s}$ (in eight and six subjects respectively) while two minute periods of muscle vibration were alternated with control periods of two minutes. The duration of the experiments was at least 12 minutes.

\section{Results}

INFLUENCE OF REFLEX REPETITION RATE ON LATE EMG RESPONSES

When $\mathrm{T}$ or $\mathrm{H}$ reflexes were evoked in the relaxed soleus muscle with frequencies lower than $3 / \mathrm{s}$, late EMG responses were seldom seen. However, at higher frequencies they could be observed regularly, mostly not immediately at the beginning of an experiment but after a number of reflexes, 
varying from several hundreds to several thousands, had been evoked. Figure 1a shows $T$ reflexes, evoked at $300 \mathrm{~ms}$ intervals. at the beginning of an experiment. After 5 min the reflexes were followed regularly by a small asynchronous discharge with a latency of $180 \mathrm{~ms}$ frcm the reflex stimulus (Fig. Ib). If the stimulus frequency was suddenly lowered during the preserice of late responses, clonus-like oscillations could be scen (Fig. 1c). Although such oscillations generally damped out rapidly, they persisted longer in proportion to the duration of the experiment. At the onset of the recording shown in Fig. 1d. the interstimulus interval was suddenly increased from 360 to $400 \mathrm{~ms}$. In this case the oscillations damped

a

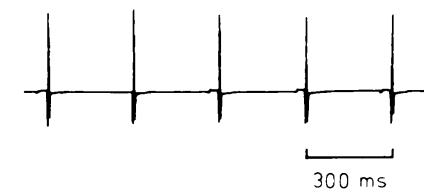

b

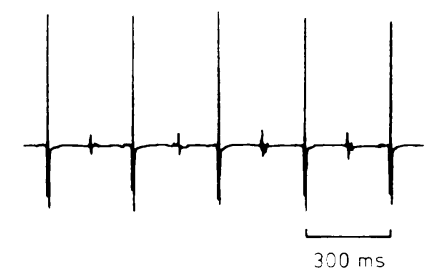

C

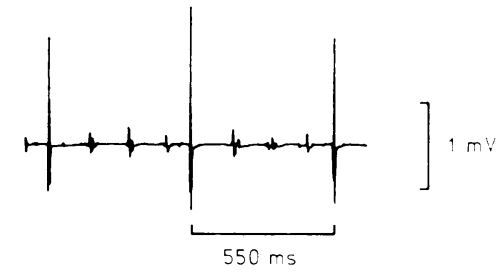

d

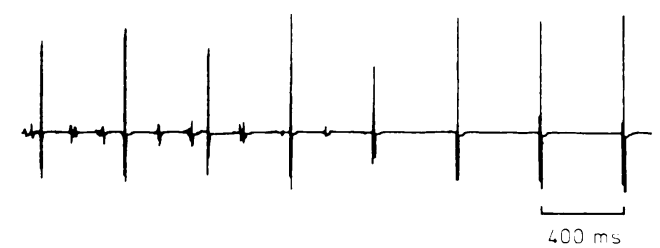

Fig. 17 reflexes in soleus muscle, evoked at intervals of $300 \mathrm{~ms}$, at the beginning of an experiment (a) and after 5 min of continuous tendon tapping (b). If thereatter the interval was suddenly increased, clonus-like oscillations could be seen (c). At the onset of record d the interval wa; suddenly increased from 300 to $400 \mathrm{~ms}$. The oscillations damped out within a few seconds. out within a few seconds. If the stimulus frequency was then increased. the late response appeared again. The EMG recordings from the anterior tibial muscle showed that the antagonists were not involved in the lase responscs.

Late responses were clearly seen in $37 \%$ of all investigated subjects. They appeared as frequently after $\mathrm{T}$ as after $\mathrm{H}$ reflexes. In the case of $T$ reflexes we had the impression that they were related to the briskness of the reflex. In some of the subjects the background EMG was not competely silent. in spite of the instruction to remain relaxed. We agree with the observation of Siein and Bawa (1976) that late responses are generally more prominent at shorter muscle longths. We worked under conditions which favcured a rather short length of the soleus muscle. This has ine advantage that the duration of the contraction is relatively short (Bawa and Sicin. 1976) so that successive monosinaptic reflex coniractions do rot infuence each other.

REIATION BEIWFEN AMPLITLIDE OF REILEXES ANI) L.IT: EMG RESPONSES

Once the late EMG respenses had appeared, their magnitude was frequently related to the amplitude of the $\mathrm{T}$ or $\mathrm{H}$ reflexes (Figs. 2 and 3). Starting frem the awsumption that $\bar{T}$ and $H$ reflexes are

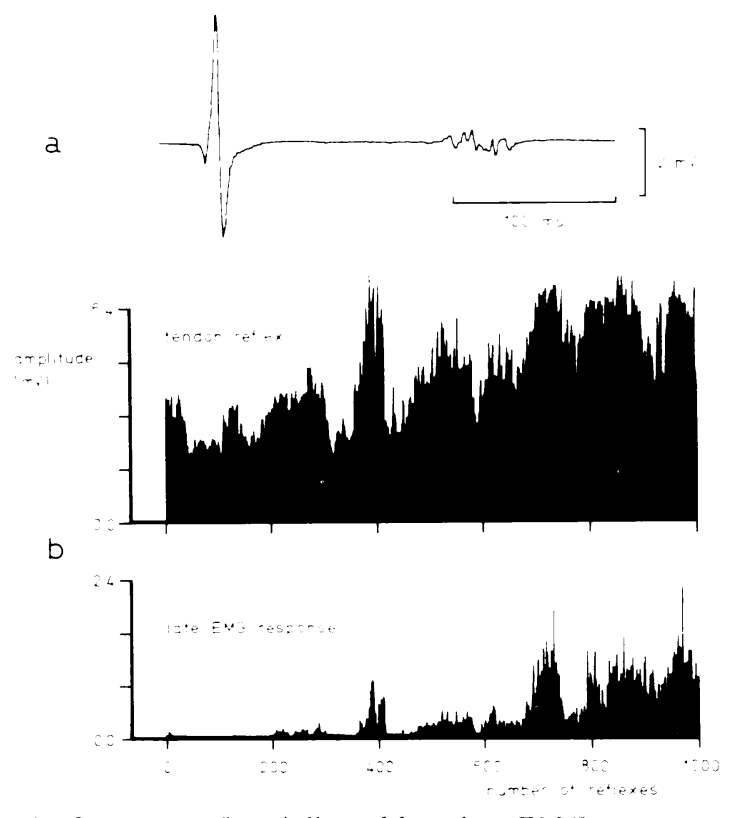

Fis. 2 (a) T reflex, followed by a late EMG re ponie, cind forming part of a sucusnce of 1003 reflexes evoked at a rate of $3 / \mathrm{s}$. (b) Peak-to-pack ampitudes of $T$ reflexes and late EMG responies. 


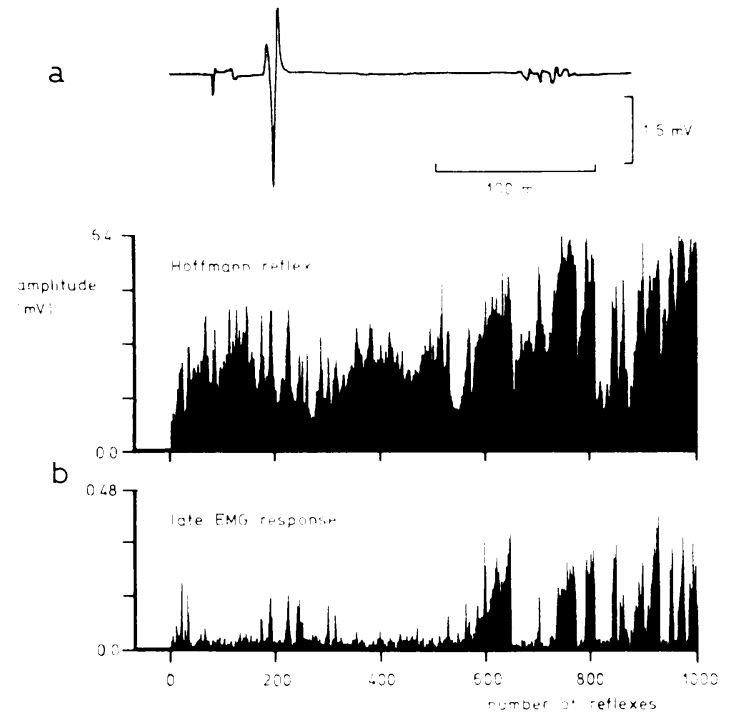

Fig. 3 (a) $H$ reflex, followed by a late EMG response, and forming part of a sequence of 1000 reflexes evoked at a rate of $3 / \mathrm{s}$. (b) Peak-to-peak amplitudes of $H$ reflexes and late $E M G$ responses.

transmitted via the same monosynaptic circuit, we have attempted to uncover common sources of variation. Variations in the muscle spindle sensitivity cannot be considered as such a common factor because the $\mathrm{H}$ reflex bypasses the muscle spindles. A plausible explanation of the covariation is that the amplitude of the late response is determined by the strength of the preceding twitch contraction. To test this hypothesis we have done experiments in which a large direct motor response and small $\mathrm{H}$ reflexes were evoked. In this case the strength of the twitch is almost completely determined by the motor response. Nevertheless the late response still covaries with the amplitude of the $\mathrm{H}$ reflex (Fig. 4). We conclude that the common source of variation must be sought in central parts of the reflex arc and that the strength of the twitch is not of primary importance in determining the late response. When the central factors mainly concern changes in alpha motoneurone excitability, possibly caused by small but unintentional isometric contractions. the alpha-gamma coactivation principle (references in Hagbarth et al., 1975a) predicts that muscle spindle sensitivity covaries with the strength of the late response. However, this would be an indirect correlation. There is no causal relationship.

Our tentative conclusion, that the strength of the twitch is unimportant compared with central
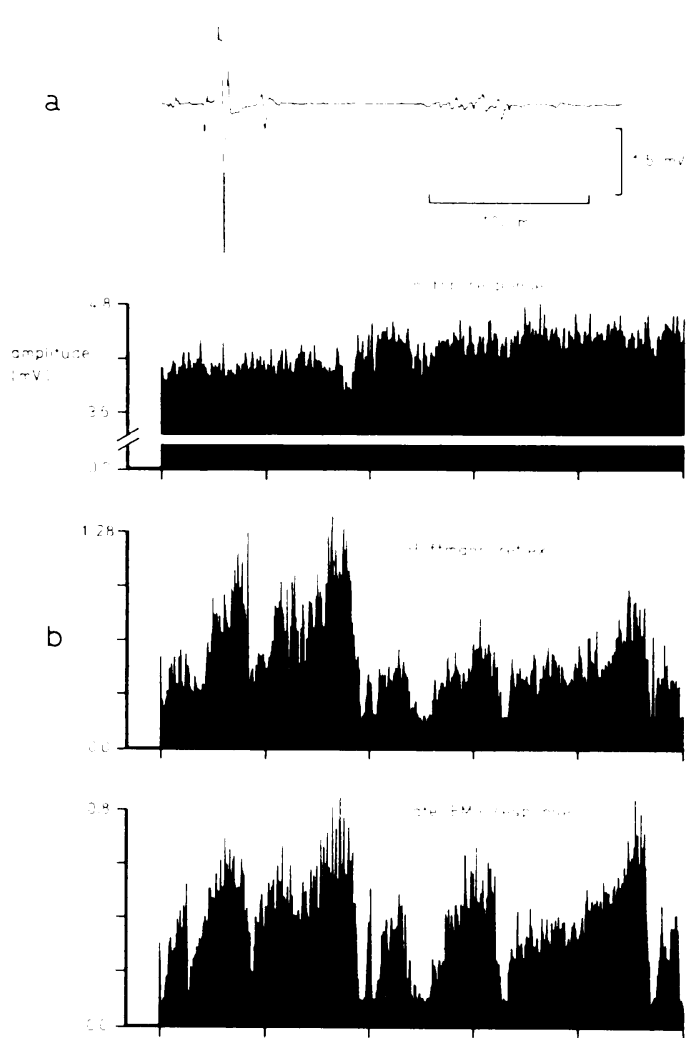

Fig. 4 (a) Small $H$ reflex, preceded by a large direct motor response and followed by a late EMG response, and forming part of a sequence of $1000 \mathrm{H}$ reflexes evoked at a rate of $3 / \mathrm{s}$. (b) Peak-to-peak amplitudes of motor responses, $H$ reflexes and late $E M G$ responses.

factors in determining the late EMG response. is strengthened by results of experiments in which $\mathrm{T}$ and $\mathrm{H}$ reflexes were evoked alternately in the same leg. It is interesting to observe the variations in the late response amplitudes when the amplitudes of $\mathrm{T}$ and $\mathrm{H}$ reflexes alter in opposite directions. Figure 5 shows such an experiment. The $\mathrm{H}$ reflex shows a few transient increases in amplitude which are accompanied with a decrease of $T$ reflexes. When $\mathrm{T}$ and $\mathrm{H}$ reflexes are elicited alternately at intervals of $333 \mathrm{~ms}$ they may be expected to have reciprocal inhibitory influences because of the dominating autogenic inhibitory effects of secondary spindle endings immediately after the end of the relaxation phase of the twitch contraction (Bianconi et al. 1964). As a consequence. an increase in $\mathrm{H}$ reflexes will be accompanied by a decrease of $T$ reflexes or vice versa. It is essential 

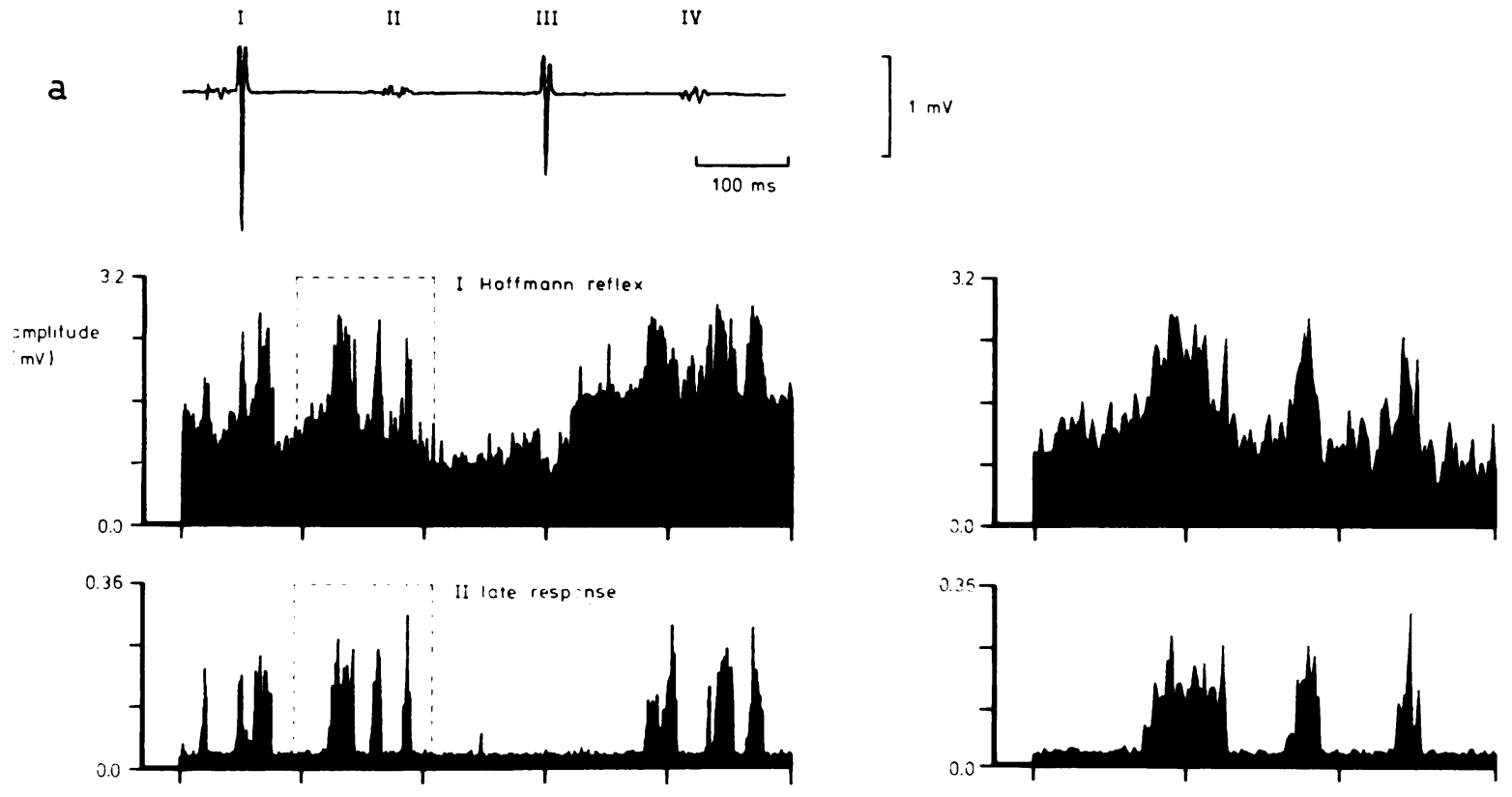

b
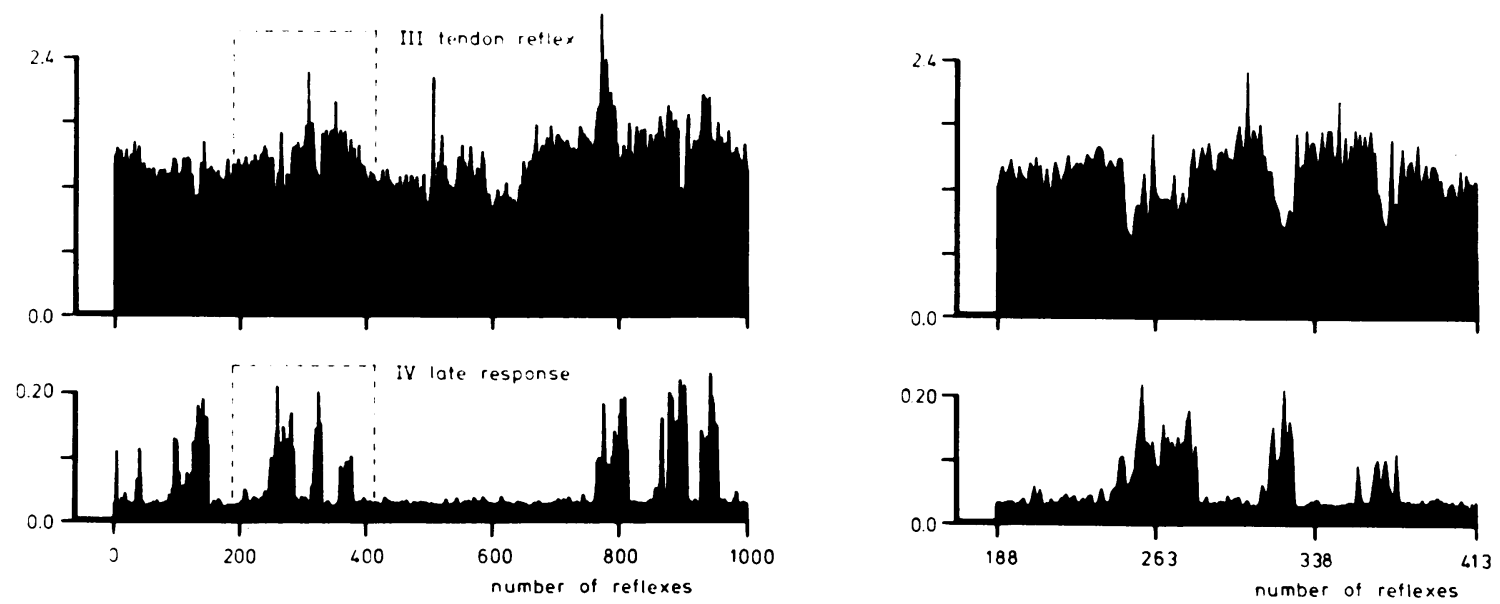

Fig. 5 (a) $H$ and $T$ reflex, followed by late EMG responses, and forming part of a sequence of 2000 reflexes (1000 $\mathrm{H}$ and $1000 \mathrm{~T}$ reflexes), alternately evoked at a rate of $3 / \mathrm{s}$. (b) Peak-to-peak amplitudes of reflexes and late responses. The part of the curve within the dashed line shows reciprocal changes in $H$ and $T$ reflex amplitudes and is shown at the right on an extended scale.

to the results that late responses, after $T$ reflexes, do not vary with $T$ reflex but with $H$ reflex amplitude.

The parallel modulation of skeletomotor and fusimotor outputs during isometric contractions (Hagbarth and Vallbo, 1968; Vallbo, 1974) implies that a weak voluntary contraction of the soleus muscle may be expected to result in a parallel increase in $T$ and $H$ reflexes and late responses when $\mathrm{T}$ and $\mathrm{H}$ reflexes are evoked in the same leg. The results were generally in agreement with this expectation (Fig. 6).

EFFECT OF VIBRATION ON LATE EMG RESPONSES

Vibration of the muscle belly is less effective than vibration of the tendon in eliciting a tonic vibration reflex (TVR) (Hagbarth and Eklund, 1966). In most of the subjects we have tested, a TVR 
a
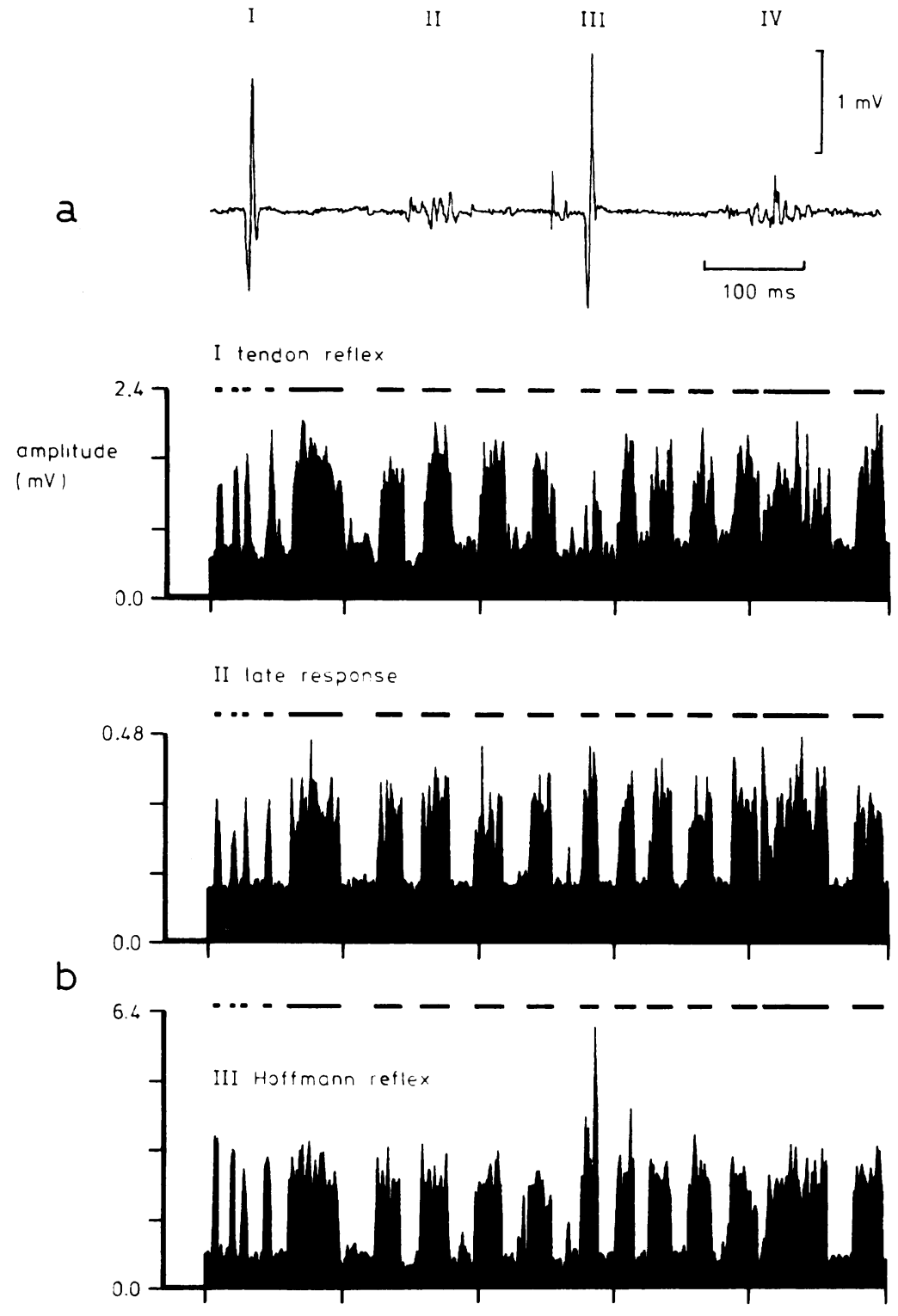

IV late response

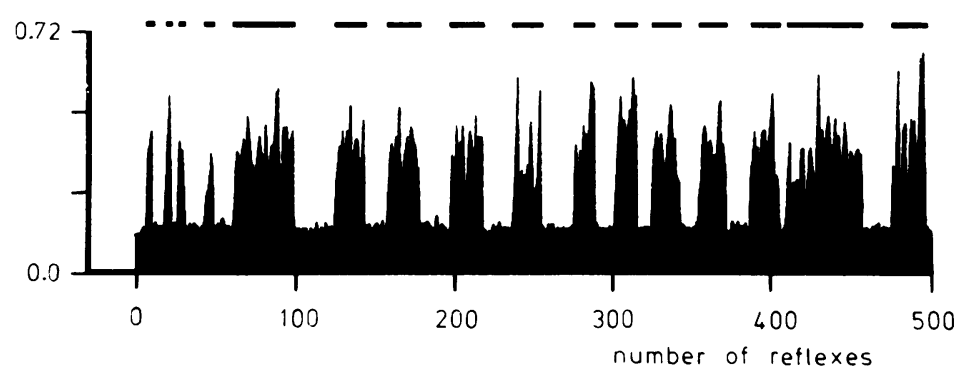

Fig. 6 (a) $T$ and $H$ reflex, followed by late EMG responses, and forming part of a sequence of 1000 reflexes (500 $\mathrm{T}$ and $500 \mathrm{H}$ reflexes), alternately evoked at a rate of 3/s. (b) Peak-to-peak

amplitudes of reflexes and late responses. The bars indicate weak isometric contraction of the calf muscles. 
could be avoided during vibration of the soleus muscle. In some subjects vibration seemed to have a cumulative effect: a TVR gradually developed over subsequent two minute periods of vibration.

The effects of vibration were identical for $T$ and $\mathrm{H}$ reflex conditions and were rather variable. When vibration was applied while there were no late EMG responses, three types of effects could generally be observed: (1) suppression of monosynaptic reflexes, (2) an increase of monosynaptic reflexes parallel with the emergence of late responses, (3) the appearance of late responses but a decrease of monosynaptic reflexes (Fig. 7). In the second type of effect inhibitory influences on the monosynaptic reflexes were probably overruled by facilitatory influences. A small voluntary soleus contraction in reaction to the vibration could explain the facilitation of both monosynaptic and late responses. Despite the dissociation between reflexes and late responses in the third type of effect, we observed that their amplitudes were correlated during vibration. In some subjects we repeatedly observed that the late responses, a few tens of seconds after they had appeared, gradually merged into a small tonic contraction. This relation in time gave the impression that they were dependent, at least partly, on the same neural mechanisms which determine the TVR. In such cases the monosynaptic reflexes generally showed further depression.

In two cases ( $T$ reflex experiments) in which late responses were already present before vibration was applied, they were facilitated while the $T$ reflex showed a small inhibition. We did not observe that monosynaptic and late responses were both inhibited by vibration unless the $T$ reflexes were completely suppressed, which confirms that twitch-evoked input is a necessary condition for late responses.

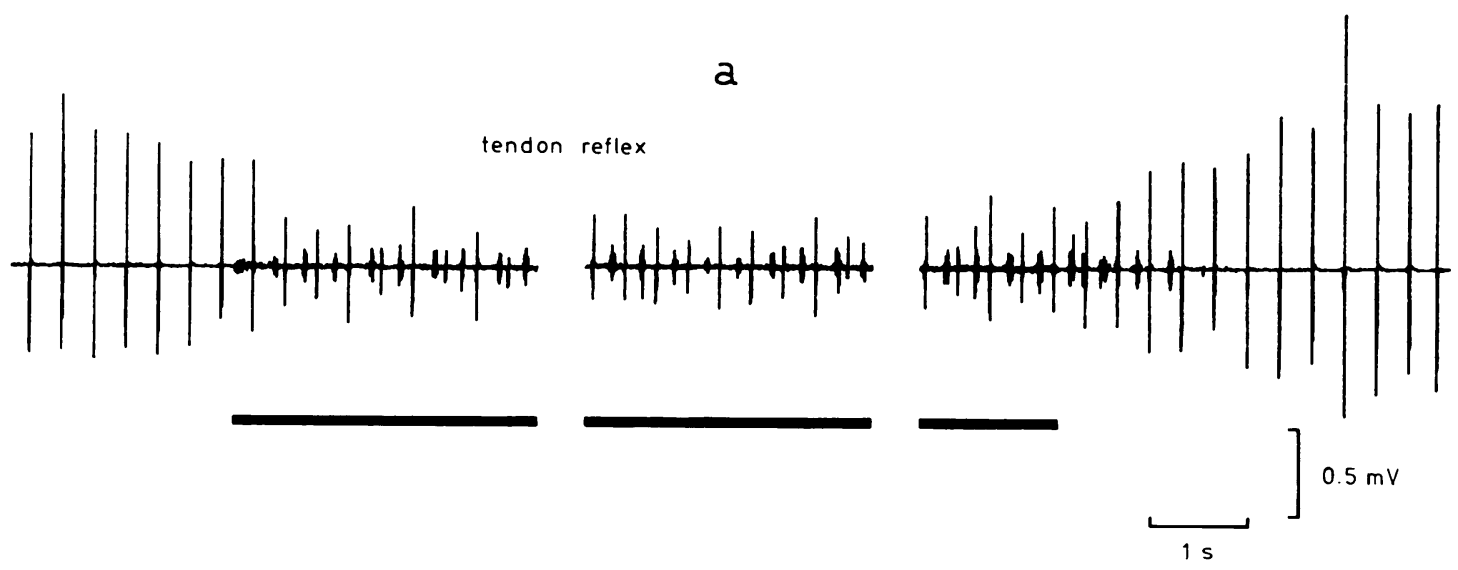

b

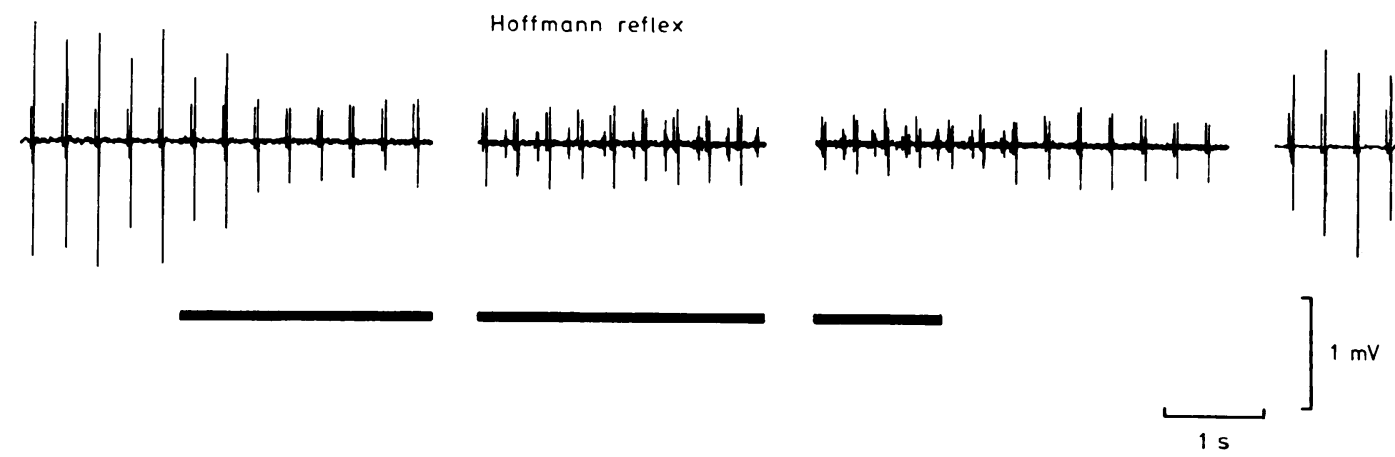

Fig. $7 \quad T(a)$ and $H$ reflexes $(b)$ evoked at the onset, in the middle and at the end of a 2 min period of $100 \mathrm{~Hz}$ vibration of the calf muscles (indicated by bars). The $\mathrm{H}$ reflex does not immediately recover after the end of vibration but regains its initial value after about $30 \mathrm{~s}$. 


\section{Discussion}

Our results are in accordance with those of Stein and Bawa (1976) in so far as they did not find late EMG responses when twitches were evoked electrically at rest at a rate of one every three seconds. However, we regularly found them at frequencies higher than $2 / \mathrm{s}$. Two different explanations may be advanced. The first is that the subjects unintentionally made weak voluntary contractions in the calf muscles in response to the imposed perturbations. The absence of background EMG activity in surface recordings is no guarantee that extrafusal activity never occurs (Hagbarth et al., 1975a). Another explanation is proposed by Gottlieb and Agarwal (1977) who found that passive oscillatory movements of the foot, when applied for at least several minutes, can produce sustained ankle clonus lasting for many seconds. They presume that rhythmic stretching increases the excitability within the spinal cord. Both explanations are compatible with the observed correlation between monosynaptic reflexes and late responses in this study.

The dissociation of monosynaptic and late responses during vibration, which we found in some of the subjects, is not consistent with the view that both are transmitted by the same monosynaptic pathway. We suggest that the late responses are transmitted, at least partly, by the spinal polysynaptic pathway which plays an important role in the TVR (Kanda, 1972). Vibration of the triceps surae muscles generates a steady excitatory postsynaptic potential (EPSP) in the homonymous motoneurones which increments during sustained vibration and slowly decays after vibration has stopped (Homma and Kanda, 1973). This potential is presumably the result of activation of a polysynaptic pathway by primary endings. The steady EPSP and the late responses show similarities in time course: both develop gradually and persist some while after removal of stimulation. The fast sequence of Ia afferent volleys in our experiments might have resulted in a steady EPSP. Homma et al. (1975) electrically stimulated nerves to the gastrocnemius muscle in the cat with frequencies as low as $16 \mathrm{~Hz}$ and also found an incremental steady EPSP which made the motoneurone discharge after some time of stimulation. Activation of the polysynaptic circuit could explain our results as follows. The concurrent rise of monosynaptic reflexes and late EMG responses, when no vibration was applied, would be the result of increased biasing of the alpha motoneurones through the polysynaptic circuit. The emergence of late responses during vibration, while monosynaptic reflexes were presynaptically blocked, would be caused by twitchevoked excitation of the polysynaptic pathway, superimposed on excitation by the vibratory afferent impulses. This would result in sufficient depolarisation of the alpha motoneurones to cross the discharge threshold, synchronously with the twitch-evoked afferent volleys.

This explanation is reconcilable with that of Gottlieb and Agarwal (1977) mentioned above. It may be questioned why, during vibration, the polysynaptic circuit would be excited by twitchinduced volleys in the primary spindle endings and not by responses to tendon tap or electric shock. In the former case, asynchronous volleys of rather long duration may be expected while in the latter case there will be short synchronous volleys (Granit and Van der Meulen, 1962; Wallin et al., 1973; Szumski et al., 1974; Hagbarth et al., 1975a). It is conceivable that only the twitch-induced volleys are able to make the motoneurones discharge through the polysynaptic pathway because of temporal summation at the level of the interneurones.

In general, our hypothesis on the role of a polysynaptic circuit in ankle clonus in spastic patients is consistent with earlier findings: (1) spasticity is accompanied by faster recovery of $\mathrm{H}$ reflexes to conditioning stimuli, indicating increased central excitability (Diamantopoulos and Zander Olsen, 1967; Delwaide, 1971); (2) spastic patients do not show signs of increased dynamic spindle sensitivity (Hagbarth et al., 1973); (3) the TVR in spastic subjects develops more rapidly than in normal subjects (Hagbarth and Eklund, 1968; Burke et al., 1972); (4) vibration of spastic muscles may induce clonus superimposed on a TVR (Kanda et al., 1973).

We would suggest that exaggerated clonic oscillations in spastic patients are related to hyperexcitability of the polysynaptic connection between Ia afferent nerve fibres and alpha motoneurones. Other disturbances, such as a reduction of presynaptic inhibition acting on the Ia afferent fibres (Delwaide, 1971) may also contribute.

\section{References}

Agarwal, G. C., and Gottlieb, G. L. (1972). The muscle silent period and reciprocal inhibition in man. Journal of Neurology, Neurosurgery, and Psychiatry, 35, 72-76.

Bawa, P., and Stein, R. B. (1976). Frequency response of human soleus muscle. Journal of Neurophysiology, 39, 788-793. 
Bianconi, R., Granit, R., and Reis, D. J. (1964). The effects of extensor muscle spindles and tendon organs on homonymous motoneurones in relation to $\gamma$-bias and curarization. Acta Physiologica Scandinavica, 61, 331-347.

Burke, D., Andrews, C. J., and Lance, J. W. (1972). Tonic vibration reflex in spasticity, Parkinson's disease, and normal subjects. Journal of Neurology, Neurosurgery, and Psychiatry, 35, 477-486.

Burke, D., Hagbarth, K.-E., Löfstedt, L., and Wallin, B. G. (1976). The responses of human muscle spindle endings to vibration of non-contracting muscles. Journal of Physiology, 261, 673-693.

Delwaide, P. J. (1971). Etude expérimentale de l'hyperréflexie tendineuse en clinique neurologique. Editions Arscia SA: Brussels.

Diamantopoulos, E., and Zander Olsen, P. (1967). Excitability of motor neurones in spinal shock in man. Journal of Neurology, Neurosurgery, and Psychiatry, 30, 427-431.

Dindar, F., and Verrier, M. (1975). Studies on the receptor responsible for vibration induced inhibition of monosynaptic reflexes in man. Journal of Neurology, Neurosurgery, and Psychiatry, 38, 155-160.

Dietrichson, P. (1973). The role of the fusimotor system in spasticity and Parkinsonian rigidity. In New Developments in Electromyography and Clinical Neurophysiology, vol. 3, pp. 496-507. Edited by J. E. Desmedt. Karger: Basel.

Gassel, M. M. (1970a). The role of skin areas adjacent to extensor muscles in motor neurone excitability: evidence bearing on the physiology of Babinski's response. Journal of Neurology, Neurosurgery, and Psychiatry, 33, 121-126.

Gassel, M. M. (1970b). A critical review of evidence concerning long-loop reflexes excited by muscle afferents in man. Journal of Neurology, Neurosurgery, and Psychiatry, 33, 358-362.

Gillies, J. D., Lance, J. W., Neilson, P. D., and Tassarini, C. A. (1969). Presynaptic inhibition of the monosynaptic reflex by vibration. Journal of Physiology, 205, 329-339.

Gottlieb, G. L., and Agarwal, G. C. (1977). Physiological clonus in man. Experimental Neurology, $54,616-621$.

Granit, R., and Van der Meulen, J. P. (1962). The pause during contraction in the discharge of the spindle afferents from primary end organs in cat extensor muscles. Acta Physiologica Scandinavica, 55, 231-244.

Hagbarth, K.-E., and Eklund, G. (1966). Motor effects of vibratory muscle stimuli in man. In Muscular Afferents and Motor Control, pp. 177-186. Edited by R. Granit. Stockholm: Almqvist and Wiksell.

Hagbarth, K.-E., and Eklund, G. (1968). The effects of muscle vibration in spasticity, rigidity and cerebellar disorders. Journal of Neurology, Neurosurgery, and Psychiatry, 31, 207-213.

Hagbarth, K.-E., and Vallbo, A. B. (1968). Discharge characteristics of human muscle afferents during muscle stretch and contraction. Experimental Neurology, 22, 674-694.

Hagbarth, K.-E., Wallin, G., Burke, L., and Löfstedt, L. (1975a). Effects of the Jendrassik manoeuvre on muscle spindle activity in man. Journal of Neurology, Neurosurgery, and Psychiatry, 38, 1143-1153.

Hagbarth, K.-E., Wallin, G., and Löfstedt, L. (1973). Muscle spindle responses to stretch in normal and spastic subjects. Scandinavian Journal of Rehabilitation Medicine, 5, 156-159.

Hagbarth, K.-E., Wallin, G., Löfstedt, L., and Aquilonius, S.-M. (1975b). Muscle spindle activity in alternating tremor of Parkinsonism and in clonus. Journal of Neurology, Neurosurgery, and Psychiatry, 38, 636-641.

Hayes, K. C., and Clarke, A. M. (1978). Facilitation of late reflexes in humans during the preparatory period of voluntary movement. Brain Research, 153, 176-182.

Homma, S., and Kanda, K. (1973). Impulse decoding process in stretch reflex. In Motor Control, pp. 4564. Edited by A. A. Gydikov, N. T. Tankov, and D. S. Kosarov. New York: Plenum Press.

Homma, S., Mizote, M., and Watanabe, S. (1975). Participation of mono- and polysynaptic transmission during tonic activation of the stretch reflex arcs. Japanese Journal of Physiology, 25, 135-146.

Kanda, K. (1972). Contribution of polysynaptic pathways to the tonic vibration reflex. Japanese Journal of Physiology, 22, 367-377.

Kanda, K., Homma, S., and Watanabe, S. (1973). Vibration reflex in spastic patients. In New Developments in Electromyography and Clinical Neurophysiology, vol. 3, pp. 469-474. Edited by J. E. Desmedt. Karger: Basel.

Katz, R., Morin, C., Pierrot-Deseilligny, E., and Hibino, R. (1977). Conditioning of $\mathbf{H}$ reflex by a preceding subthreshold tendon reflex stimulus. Journal of Neurology, Neurosurgery, and Psychiatry, 40, 575-580.

Masland, W. S. (1972). Facilitation during the Hreflex recovery cycle. Archives of Neurology (Chicago), 26, 313-319.

Robinson, K. L., McIlwain, J. S., and Hayes, K. C. (1979). Effects of H-reflex conditioning upon the contralateral alpha motoneuron pool. Electroencephalography and Clinical Neurophysiology, 46, 65-71.

Stein, R. B., and Bawa, P. (1976). Reflex responses of human soleus muscle to small perturbations. Journal of Neurophysiology, 39, 1105-1116.

Szumski, A. J., Burg, D., Struppler, A., and Velho, F. (1974). Activity of muscle spindles during muscle twitch and clonus in normal and spastic human subjects. Electroencephalography and Clinical Neurophysiology, 37, 589-597.

Tábořiková, H., and Sax, D. S. (1969). Conditioning of H-reflexes by a preceding subthreshold H-reflex stimulus. Brain, 92, 203-212.

Vallbo, A. B. (1974). Human muscle spindle dis- 
charge during isometric voluntary contractions. Amplitude relations between spindle frequency and torque. Acta Physiologica Scandinavica, 90, 319336.

Wallin, B. G., Hongell, A., and Hagbarth, K.-E.
(1973). Recordings from muscle afferents in Parkinsonian rigidity. In New Developments in Electromyography and Clinical Neurophysiology, vol. 3, pp. 263-272. Edited by J. E. Desmedt. Karger: Basel. 